\section{Ghanaian SMEs' perspective on the interrelationship between market and entrepreneurial orientations}

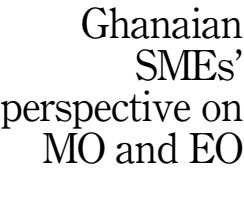

Department of Marketing and Supply Chain Management, University of Cape Coast, Cape Coast, Ghana

Sanjay Soni

University of KwaZulu-Natal, Durban, South Africa, and

Innocent Senyo Kwasi Acquah

Department of Marketing and Supply Chain Management, University of Cape Coast, Cape Coast, Ghana

\begin{abstract}
Purpose - This research examines the interrelationships between market orientation (MO) and entrepreneurial orientation (EO) in the small- and medium-sized enterprise (SME) sector. Due to the conflicting results associated with each orientation's influence on firm performance, some researchers advanced that scholars should resort to concurrent observation of the constructs. To the researchers, concurrent deployment of the constructs by businesses is likely to result in an enhanced performance. However, what is lacking in their proposition is how the deployment of these resources should be, thereby leading to a knowledge gap in the literature. The aforementioned gap is what this paper seeks to address.

Design/methodology/approach - The study employed deductive research approach, and data were collected from 366 SMEs' owners or owner-managers of SMEs in two metropoles in Ghana. For this study, the hand delivery and collection of questionnaire technique was deployed. The reason is that most respondents may be reluctant to respond to the questionnaires through the post or Internet. Partial least square-structural equation modelling (PLS-SEM) was employed for the data analysis due to its importance in allowing the testing of relationships among constructs. Furthermore, seven-point Likert scale was used to generate responses from the respondents.

Findings - The result indicates that MO and EO have a positive and significant influence on each other. However, the influence of EO on MO is greater. Therefore, when owners of SMEs are embracing the two constructs in their businesses, EO should precede MO. The finding is a novelty of this study. Through this result, the owners of SMEs would have knowledge of embracing EO before MO during the employment of the two constructs in their firms. The study further revealed that not all the components of MO have positive and significant influence on $\mathrm{EO}$, and the reverse is true. Without this study, the owners of SMEs would have placed equal attention on each construct and their components. The study also indicates that deployment of MO in its composite form rather than components is the best way for improving EO.

Practical implications - The more SMEs engage in MO activities, the likelihood of an increase in their entrepreneurial spirit and the opposite is true. However, engaging in more EO activities would result in higher MO than the reverse.

Originality/value - The findings add to the empirical literature by revealing the interrelationships between $\mathrm{MO}$ and EO, which serve as a guide to owners of SMEs and practitioners in their concurrent deployment of the two constructs. The findings would also open replication doors for future researchers in different settings.

Keywords Ghanaian, SMEs, Interrelationship, Market orientation, Entrepreneurial orientation, PLS-SEM

Paper type Research paper

(C) Kassimu Issau, Sanjay Soni and Innocent Senyo Kwasi Acquah. Published in Revista de Gestão. Published by Emerald Publishing Limited. This article is published under the Creative Commons Attribution (CCBY 4.0) licence. Anyone may reproduce, distribute, translate and create derivative works of this article (for both commercial and non-commercial purposes), subject to full attribution to the original publication and authors. The full terms of this licence may be seen at http://creativecommons. org/licences/by/4.0/legalcode
\end{abstract}

Received 26 March 2021 Revised 28 July 2021 24 August 2021

Accepted 19 September 2021 
REGE

29,2

140

\section{Introduction}

Globalisation has heightened competition among firms across the globe. Failure for firms to adjust to such environment threatens their survival and growth. The consequences that may result include job losses and increase in poverty, particularly in unindustrialised countries. According to Rahman, Yaacob and Radzi (2016), marketing and financial issues are among the factors that impede performance of small- and medium-sized enterprises (SMEs). Machado, Gaiotto and Machado (2021) also opined that lack of machinery and materials are among the factors that hinder growth of entrepreneurs. In the view of Ocloo, Akaba and Worwui-Brown (2014), problems of SMEs in Ghana are deepened by strong global competition. To Asomaning and Abdulai (2015), lack of deployment of elements such as market orientation (MO) and entrepreneurial orientation (EO) is the cause of the poor performance of SMEs in Ghana. Opoku (2017) indicated that the growing failure rate of SMEs in Ghana is due to their poor performances. However, since MO and EO are the essential components identified in the literature as propellants of SMEs' performance, their investigation within the context of SMEs is admissible because of the role played by SMEs in different countries. Relying on the resource-based view (RBV) - which contends that a firm's competitive position and performance is influenced by the kind of resources and capabilities it possesses (Peteraf \& Barney, 2003) - MO and EO can be considered "soft" or intangible resources with characteristics such as "valuable", "rare", "inimitable" and "nonsubstitutable" that can provide performance differentials to firms that harbour them. In support, Lonial and Carter (2015) claimed that MO and EO are important resources that have aforementioned characteristics needed for successful performance. Thus, MO, which shows the extent to which an establishment's strategies and operations are strengthened to respond to market demands (Kohli \& Jaworski, 1990), could be seen as having the aforementioned desirable resource characteristics because of its innate nature. The same can be said for EO, which exhibits a reflection of what is in the minds of decision-makers, focusing on creating new establishments, sustaining the vision of the establishments, and achieving competitive advantage in the market arena (Lumpkin \& Dess, 1996).

Because of the importance attached to $\mathrm{MO}$ and $\mathrm{EO}$, prior researchers carried out studies to determine how each construct contributes to performance. However, conflicting results were seen from the studies. With respect to the link between $\mathrm{MO}$ and firm performance, results of their findings are yet to converge to one point (Shehu, 2014). For example, whilst studies by Hussain, Ismail and Shah (2015), Gruber-Muecke and Hofer (2015), Amin, Thurasamy, Aldakhil and Kaswuri (2016), and Issau and Soni (2019) established positive link, Gholami and Birjandi (2016) established negative nexus. Nevertheless, the conclusion reached by Cano, Carrillat and Jaramillo (2004) in their thorough examination of $200 \mathrm{MO}$ publications revealed that $\mathrm{MO}$ has a significant influence on firm performance. Furthermore, Issau, Acquah, Gnankob and Hamidu's (2021) conclusion on market innovation and SMEs' performance is a confirmation of MOs' importance to the improvement of SMEs' performance. Agreeably, a stream of studies by Hussain et al. (2015), and Amin et al. (2016) on the effect of MO on SMEs' performance all supported the positive impact claim between the two variables. Noble, Sinha and Kumar (2002) asserted that the conflicting results might be ascribed to issues in methodology relating to the scaling of $\mathrm{MO}$ and the usage of different performance measures. However, current studies (Hussain et al., 2015; Amin et al., 2016) seem to favour positive linkages between the two constructs. This is not surprising, given the fact that there is enough time lag for current researchers to overcome the challenges of previous scholars and for owners of SMEs to overcome the implementation challenges of MO.

Furthermore, though many scholars (Hussain et al., 2015; Gruber-Muecke \& Hofer, 2015; dos Santos \& Marinho, 2018) have established a positive node between EO and performance, some of the investigations fail to determine the positive nexus between the constructs (Pelham, 2000). Additionally, whilst studies by authors, such as Hussain et al. (2015) and 
Nasir, Al Mamum and Breen (2017), have recorded significant positive nexuses between EO and SMEs' performance, others, such as Affendy, Asmat-Nizam and Farid (2015), failed to record a significant nexus between the constructs. Though mixed results have been established on the EO-performance linkage, the positive nexus is supported by many empirical studies (e.g. Hussain et al., 2015).

Due to the conflicting results associated with each orientation's influence on firm performance, researchers such as Lonial and Carter (2015), Nasir et al. (2017) and Issau and Soni (2019) advanced that scholars should resort to concurrent observation of the constructs. To these researchers, concurrent deployment of the constructs by businesses is likely to result in an enhanced performance. The viewpoint held by the authors could be agreed upon because each of the two constructs has been established in the literature as a performance differential resource. However, what is lacking in their proposition is how the constructs influence each other. The researchers failed to determine the interaction of these performance differential resources, thereby leading to a knowledge gap in the literature on how the deployment of these resources should be. The intriguing question is as follows: Should EO be the first resource to be employed by businesses or MO during their concurrent deployment by establishments? What are the reasons for supporting any of the positions? Do the two constructs affect each other? These knowledge gaps are what this paper seeks to address. The purpose of this study, therefore, is to examine the interrelationships between $\mathrm{MO}$ and $\mathrm{EO}$ in the SME sector.

In Ghana, SMEs may be grouped into urban and rural businesses. The former can be sub-divided into "organised" and "unorganised" businesses (Kayanula \& Quartey, 2000). Kayanula and Quartey (2000) postulated that the "organised" ones are those having paid employees with registered offices, while the "unorganised" ones are those operating in temporary wooden structures, sometimes with no salaried workers. This study concentrates on "urban-organised" SMEs because they have the potential for growth and expansion needed for economic and social development and well-being (Lingelbach, De La Vina, \& Asel, 2005). The originality of the current study is in the fact that its findings add to the empirical literature by revealing the interrelationships between $\mathrm{MO}$ and $\mathrm{EO}$, which serve as a guide to owners of SMEs and practitioners in their concurrent deployment of the two constructs. The findings would also open replication doors for future researchers in different settings.

\section{Literature review and hypotheses development \\ Market orientation}

Marketing literature has seen enormous contributions from different investigators on MO. MO shows the extent to which an establishment's strategies and operations are strengthened to respond to market demands. Researchers (Gruber-Muecke \& Hofer, 2015; Prifti \& Alimehmeti, 2017) have described the construct in different ways. Though various perspectives on MO exist, researchers (Gholami \& Birjandi, 2016; Gruber-Muecke \& Hofer, 2015; Issau, 2019) endorsed behavioural and cultural approaches. Next is the explanation of the perspectives.

\section{Cultural perspective}

From the perspectives of Narver and Slater (1990) and Gholami and Birjandi (2016), the cultural aspect of MO can be achieved through the implementation of three things by an establishment. First, "a firm must understand its customers' needs and create superior value to satisfy those needs". Second, "a firm must understand the strengths and weaknesses of its opponents", which will serve as a guard to the products that it can offer to its clients. Finally, "a firm must coordinate all its functional activities in order to create value for buyers". The 
REGE

29,2

142

views of the authors indicate that three conditions must be present for a firm to qualify as a market-oriented one. The first condition is that a firm must generate enough information about its customers, sufficient to understanding their current and future needs to be able to create constant superior value for them. The second condition is that much information must also be generated from the firm's competitors in order to understand their strengths, weaknesses and tactics. Finally, the information generated by a firm must be shared across the entire organisation for various units of such an organisation to contribute their quota in the creation of better value for clients. This presupposes that MO is beyond the capability of the marketing department and, therefore, must be undertaken by every unit of an organisation for the creation of superior value for customers to ensue.

\section{Behavioural perspective}

Prifti and Alimehmeti (2017) and Kohli and Jaworski (1990) offered a different perspective to $\mathrm{MO}$, showing that $\mathrm{MO}$ comprises three behavioural components: "organisation-wide generation of market intelligence, dissemination of the intelligence and organisation-wide responsiveness to the intelligence". This means that a firm that engages in activities geared towards the comprehension of customers' needs, the sharing of the understanding among units and the units engaging in activities designed to handle those needs is a marketoriented one.

From both perspectives, it can be said that MO is a responsibility of the entire organisation and not only the marketing department. However, the dissimilarity between the two perspectives is that while a cultural perspective was emphatic about the kind of information (customer and competitor) to be sought in the marketplace (which makes it most preferred), the behavioural perspective sought to generate information from the market in general. The problem that may ensue is that there is a possibility where some firms may concentrate only on the search of customer information and neglect information about competitors.

\section{Entrepreneurial orientation}

Researchers have defined EO in different ways. According to Lumpkin and Dess (1996), it is a reflection of what is in the minds of decision-makers, focusing on creating new establishments, sustaining the vision of the establishments and achieving competitive advantage in the market arena. Also, Rauch, Wiklund, Lumpkin and Frese (2009) refer to it as the processes of making strategy, methods and styles employed by key decision-makers in enacting their organisational purposes, sustaining their vision and creating competitive advantage. Miller (2011) offered the earliest conceptualisation of the construct. The author's conceptualisation provided three dimensions: "risk-taking", "innovativeness" and "proactiveness". Two additional elements were further introduced by Lumpkin and Dess (1996): "competitive aggressiveness" and "autonomy". These dimensions remain, to date, the most consistently applied operationalisation of EO in the literature (Rauch et al., 2009; Agbegblewu $\&$ Boohene, 2016). The conceptualisation of EO by Garcia, Martens, Carvalho and Martens (2021) attest to the above claim.

Also, Bature and Hin (2017) view EO as a managerial philosophy, practice and strategic posture in decision-making that indicates the display of innovative attitude, risk-taking behaviour and proactive thinking. Entrepreneurial organisations often introduce their new products first in the marketplace and frequently initiate actions in the market environment. The adoption of an EO may be beneficial to firms, more especially in today's volatile business environment, where issues are not constant with life cycles of products being shortened. Being entrepreneurial-oriented enables firms to have the edge over their rivals, thereby granting performance to the firms (Al Mamun \& Fazal, 2018). Therefore, entrepreneurship education must be used as a conduit for nurturing entrepreneurial characteristics in various 
establishments (Salamzadeh, Farjadian, Amirabadi, \& Modarresi, 2014; Awang, Amran, Nor, Ibrahim, \& Razali, 2016; Tajpour, Hosseini, \& Alizadeh, 2021), thereby granting the firms entrepreneurial potential needed for growth (Couto, Sousa, \& Pimentel, 2017). Based on the assertion by Moghadam and Salamzadeh (2018), firms must be aware of individual and organisational factors that have a tendency of influencing their entrepreneurial behaviours. In support, de Lara and Guimarães (2018) provided that personal goals and ambitions of owners of SMEs are important stimuli for entrepreneurial spirit, hence innovation. Thus, it is not surprising why the conclusion reached by Kim (2018) showed that EO studies are growing in recent years.

While Covin and Slevin (1989) claimed that EO is a one-dimensional element, Lumpkin and Dess (1996) are of the view that it is a multidimensional element and therefore must be dealt with as independent behavioural dimensions. Though EO dimensions are interconnected, the intensity of the dimensions may differ because of cultural setting (Kemelgor, 2002). Deduction can be made from this assertion that EO dimensions' influence on the dependent variable largely rely on the study's context. Covin and Slevin (1989), Agbegblewu and Boohene (2016) and Tajpour and Hosseini (2021) opined that organisations with the culture of entrepreneurship have an advantage over their rivals in a competitive business arena. In this regard, the authors averred that firms must exhibit EO qualities such as taking risks, being proactive and innovative to enhance their successes in the marketplace. This reiterates the importance of $\mathrm{EO}$ in improving performance of businesses.

\section{Market orientation and entrepreneurial orientation}

$\mathrm{MO}$ and $\mathrm{EO}$ are considered valuable resources needed for sustainable competitive advantage and performance (Long, 2013; Lonial \& Carter, 2015). They are perceived as firm-level resources and culture, which are bases for achieving lasting competitive edge (Long, 2013). These resources are often examined independently in the extant literature. However, modern investigators are trying to do away with the fragmented approach and reverse to concurrent observation of the constructs (Lonial \& Carter, 2015; Nasir et al., 2017). Though there is dearth of literature regarding how the constructs influence each other, some deductions can be made from the pioneer studies. Ramirez, Guzman and Serna (2014) are of the opinion that MO drives EO. Nonetheless, Hussain et al. (2015) opined that the two constructs affect each other, have similar characteristics and facilitate the execution of each other; thus, relying solely on one orientation and claiming that it would provide superior performance is inadequate. The authors posited that there should be a balance of both $\mathrm{MO}$ and EO in the marketplace to facilitate attainment of a remarkable performance. While the former enables the firm to provide an enhanced value to clients, the latter enables the firm to seek and exploit opportunities in the marketplace. Agreeably, Boso, Oghazi, Cadogan and Story (2016) advanced that relying simultaneously on $\mathrm{MO}$ and $\mathrm{EO}$ results in higher performance of export. Thus, their balance must be employed. From the discussion, it can be argued that the two constructs have some relationship with each other. However, the nature and extent of this relationship is what remained unknown. In the light of this, the following hypotheses were proposed:

H1. MO has a positive and significant nexus with EO.

H2. All the components of MO have a positive and significant nexus with EO.

\section{Entrepreneurial orientation and market orientation}

Agbegblewu and Boohene (2016) advanced that a firm with high entrepreneurial qualities facilitates an organisation's knowledge creation process. The authors further indicated that the knowledge creation process helps the accumulation of new knowledge and the unfreezing 
REGE

29,2

\section{4}

knowledge that has become outdated. It also enables an establishment with an entrepreneurial competency in its possession to respond to market changes appropriately in order to create competitive advantage. While SMEs' owners or firms' strategic personnel can develop quality products through the employment of MO, EO provides the motivation for such development to occur. Values of entrepreneurship can, therefore, enhance the chances of firms creating innovative products needed for attainment of competitive advantage (Agbegblewu \& Boohene, 2016). From this, it can be deduced that EO influences MO. Furthermore, to Real, Roldán and Leal (2014), firms that are highly entrepreneurial always monitor their market and respond appropriately in order to become customer service leaders. Thus, EO can be postulated as a driving force of $\mathrm{MO}$ of a firm. This view was re-echoed by Affendy et al. (2015) and Amin et al. (2016) who claimed that EO drives MO of businesses. Based on the foregoing, the following hypotheses were developed:

H3. EO has a positive and significant nexus with $\mathrm{MO}$.

H4. All the components of EO have a positive and significant nexus with MO.

The review of the literature led to the development of the conceptual framework for the study, shown in Figure 1.

\section{Research methodology}

Research design and approach

Research design is a plan or a guide which specifies how data relating to a given research should be gathered, measured and analysed (Sekaran \& Bougie, 2016). According to Sekaran and Bougie (2016), and Saunders, Lewis and Thornhill (2016), research design can be categorised into three broad categories based on the purpose of the study, namely, exploratory, descriptive and causal designs. However, Sekaran and Bougie (2016) argue that a correlational design should be used if researchers cannot testify that the independent variable is the only construct that can cause the change in the dependent variable. In line with the aforementioned, a correlational research design was utilised for this study because it would be very difficult to conclude that $\mathrm{MO}$ is the only cause of change in $\mathrm{EO}$ and vice versa.

Also, Saunders, Lewis and Thornhill (2016) asserted that approaches to research are broadly categorised into three: deduction, induction, and abduction. In the view of the authors, whereas deductive approach concentrates on the development of theory/hypothesis through the reading of the literature, an inductive approach deals with the collection of data and develops a theory after the data analysis. Neuman (2014) opined that an abductive approach is the combination of

Figure 1.

Conceptual framework

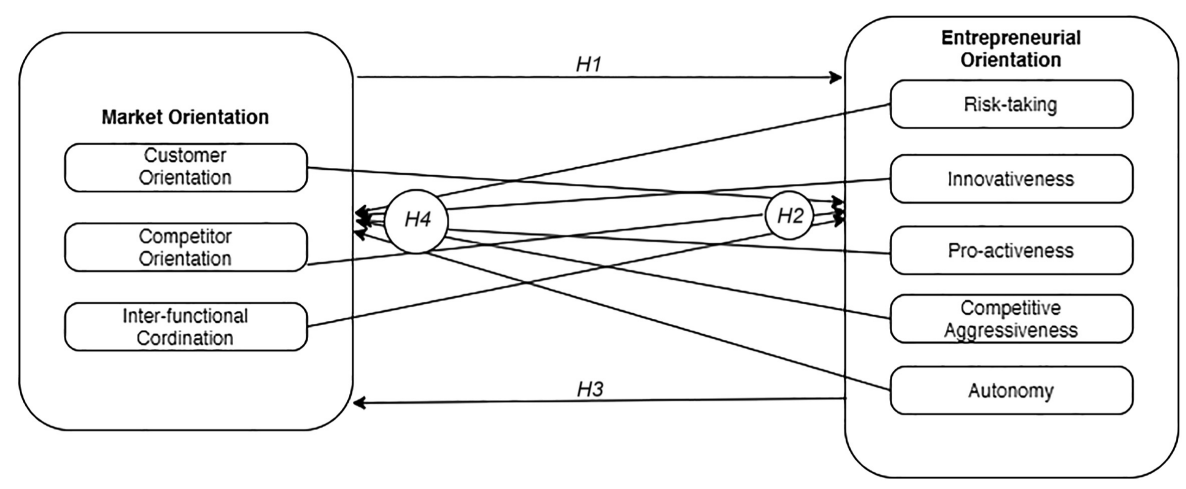


the two approaches. For this study, the deductive research approach was deemed appropriate because the current study, which relied on positivist philosophy, was quantitative in nature, which usually goes along with a deductive research approach.

\section{Population and sample size}

The population for the study was owner-managers or SMEs' owners in the Tema and Accra metropolitan areas. The National Board for Small Scale Industries (NBSSI) and the Association of Ghana Industries (AGI) were the sources of the list of study units. A sample frame for the study harbouring 7,858 SMEs in the Tema (2,045 SMEs) and Accra (5,813 SMEs) areas were obtained from AGI (2018) and NBSSI (2018). The statistical formula for sample size determination by Cooper and Schindler (2001) was used to obtain a sample size of 366, which was shared proportionately between the areas: Accra 5,813/7,858*366 $=271$ and Tema $2,045 / 7,858 * 366=95$. The sample size selection was aided by random number generation tool in Excel.

\section{Measures of market orientation and entrepreneurial orientation}

Customer orientation, competitor orientation and inter-functional coordination constructs (Narver \& Slater, 1990) and risk-taking, innovativeness, pro-activeness, competitive aggressiveness and autonomous action constructs (Lumpkin \& Dess, 1996) were, respectively, employed in measuring $\mathrm{MO}$ and $\mathrm{EO}$. Also, all the variables were reflectively measured. This is because all the study's constructs cause the measurement of the indicator variables to vary (Hair, Hult, Ringle, \& Sarstedt, 2014).

\section{Data collection procedure and analysis}

According to Sekaran and Bougie (2016) and Saunders et al. (2016), data can be gathered through the Internet, post and hand delivery and collection of questionnaires methods. For this study, the hand delivery and collection technique was deployed. The reason is that most respondents may be reluctant to respond to the questionnaires through the post or Internet. Furthermore, the collection of data took place in the third quarter of 2018. Overall, 347 questionnaires were found usable and hence utilised in this study. Partial least squarestructural equation modelling (PLS-SEM) was employed for the data analysis due to its importance in allowing the testing of relationships among constructs. According to Hair et al. (2014), PLS-SEM technique can help assess measurement and structural models simultaneously, thereby reducing error variance. Furthermore, seven-point Likert scale was used to generate responses.

\section{Findings and discussion}

The study generated four models, and they are discussed in this section. Notwithstanding, each model's discussion was preceded by the measurement model's assessment. According to Hair et al. (2014), a measurement model with loadings of indicators above 0.70 or between 0.4 and 0.7 is recommended in situations where eliminating the indicators do not cause an increase in the reliability of the model on the latent variable. Also, CR (composite reliability) score of 0.6-0.7 and AVE (average variance extracted) of $\geq 0.50$ are best for a measurement model. Finally, DV (discriminant validity) is considered appropriate for a measurement model when "the square root of each construct's AVE is higher than its correlation with other constructs" (FornellLarcker criterion) or when heterotrait-monotrait (HTMT) ratio is $<0.85$. However, of the two, HTMT ratio is more recommended because of its rigorous nature (Sarstedt, Ringle, Smith, Reams, \& Hair, 2014; Acquah, Essel, Baah, Agyabeng-Mensah, \& Afum, 2021a). Also, indicator reliability is measured by Cronbach's alpha (CA) with its cut-off point being $>0.7$, as 
REGE

29,2

\section{6}

recommended by Hair et al. (2014). According to Henseler, Ringle and Sinkovics (2009), assessment of the measurement model is required to enhance the understanding of the structural model findings.

Further, Hair et al. (2014) provided that $t$-statistic values above 1.96 with $p$-values $<0.05$ are recommended for determining the significance level of the latent variables' nexus. Cohen (1988) indicated that path coefficients of $0.10,0.30$ and 0.50 represent small, medium and large correlation, respectively. In addition, $R^{2}$ values of " $0.25,0.5$ and 0.75 " of structural models are seen as "weak, moderate and substantial", respectively (Hair et al., 2014; Acquah et al., 2021a, b). Also, $Q^{2}$ and $f^{2}$ values of " $0.02,0.15$ and 0.35 " are considered "small, medium and large", respectively, (Hair et al., 2014). The models' assessment and discussions would be based on the aforementioned criteria.

\section{Measurement model assessment (model 1)}

The first model to be assessed is Model 1. The model examined the influence of MO on EO.

\section{Item loading}

Based on the criterion of Hair et al. (2014), all the indicators that did not meet the required benchmark were deleted from the model.

\section{Construct reliability and validity}

The results of CA, CR and AVE of Model 1 are presented in Table 1. The results indicate that the measurement model is appropriate for further analysis to be undertaken. This is because the CA, CR and AVE of the measurement model, as shown in Table 1, met the set criteria as recommended by Hair et al. (2014). Thus, the measurement model has no problem regarding reliability and validity.

\section{Discriminant validity}

DV of the model was tested in order to determine the quality of the model. Based on the recommendation of Sarstedt et al. (2014), the HTMT ratio was used to examine the DV. From the result in Table 1, it was established that the model has no DV problem. Thus, it can be concluded that the constructs are distinct from each other.

\section{Significance of path coefficients}

The structural model was assessed after the measurements model's assessment. The findings of the assessment were presented in Table 1. From the table, the findings established that MO

Table 1.

Measurement and structural model results for Model 1

\begin{tabular}{|c|c|c|c|c|c|}
\hline \multicolumn{2}{|l|}{ Constructs } & $\mathrm{CA}$ & \multicolumn{2}{|c|}{$\mathrm{CR}$} & AVE \\
\hline \multirow{2}{*}{\multicolumn{2}{|c|}{$\begin{array}{l}\text { Entrepreneurial orientation } \\
\text { Market orientation }\end{array}$}} & 0.955 & \multirow{2}{*}{\multicolumn{2}{|c|}{$\begin{array}{l}0.961 \\
0.950\end{array}$}} & 0.690 \\
\hline & & 0.942 & & & 0.632 \\
\hline Structural path & $(\beta)$ & $T$-stats & $P$-value & Decision & $f^{2}$ \\
\hline Market orientation $\rightarrow$ EO & 0.509 & 13.196 & 0.000 & Supported & 0.350 \\
\hline HTMT & $R$ squared & & ed $R$ squal & & $Q$ squared \\
\hline 0.521 & 0.260 & & 0.257 & & 0.161 \\
\hline
\end{tabular}


has a significant positive nexus with $\mathrm{EO}(\beta=0.509 ; t=13.196 ; p=0.000<0.05)$. This is because the $t$-statistic of the model was 13.196, which is greater than 1.96 , with $P<0.05$. This finding is in line with the claim by Ramirez et al. (2014) that if SMEs were able to carry out MO activities of knowing customers' demand and competitors' action, and sharing those with members of the organisation, it would generate entrepreneurial spirit in the organisation. Relying on the RBV, MO can be regarded as a resource capable of enhancing the entrepreneurial spirit of SMEs. To this, it can be averred that deployment of MO activities should be encouraged by SMEs. In the light of the findings, the hypothesis that MO has a significant and positive relationship with EO is thus supported.

\section{Estimation of the model's predictive accuracy}

The estimation of the predictive accuracy of the model was facilitated by $R^{2}, f^{2}$ and $Q^{2}$ values. The results were captured in Table 1 . The $R^{2}$ result indicates that MO explains $26 \%$ of the changes in EO. This suggests that there are other variables that determine changes $(74 \%)$ in the EO. Based on the Hair et al.'s (2014) recommendation, the $26 \%$ explanation of MO to changes in EO could be considered small. Notwithstanding, the $f^{2}$ results indicate that MO had a high effect size on $\mathrm{EO}$. This means that though $\mathrm{MO}$ is not the only variable influencing the variation of $\mathrm{EO}$, its presence among the variables influencing EO's variation is important. Therefore, it must not be neglected when examining determinants of EO. The findings of $Q^{2}$ also show that MO had a medium prediction on the model. This reiterates the importance of MO in predicting EO. Based on the findings, the assertion of Ramirez et al. (2014) that MO drives EO cannot be faulted.

\section{Measurement model assessment (model 2)}

The second model to be assessed is Model 2. The model purpose is to help examine the influence of MO's components on EO. This is to determine whether each of the components has an influence on EO.

\section{Item loading}

Hair et al.'s (2014) cut-off point recommendation with respect to loadings of indicators on the latent variables was used to determine loadings of this model. Following the recommendation, four, three, four and eleven indicators of customer, competitor, interfunctional coordination and EO, respectively, met the standard set and hence were maintained. The indicators of the constructs that fell outside the recommended cut-off point were therefore deleted from the model.

\section{Construct reliability and validity}

CA, CR and AVE's results of Model 2 are shown in Table 2. From the results, it was established that the measurement model has no problem with respect to reliability and validity.

\section{Discriminant validity}

The quality of the model was tested using DV, and the result was shown in Table 2. In examining the DV of the constructs in the model, the HTMT ratio recommended by Sarstedt et al. (2014) was employed. The result shown in Table 2 depicts that the model has no DV problem because all the constructs' values were below 0.85 cut-off point recommended by Sarstedt et al. (2014).

\section{Significance of path coefficients}

The findings of the structural model's assessment are presented in Table 3 . From the table, the findings revealed that customer orientation $(\beta=0.251 ; t=3.740 ; p=0.000<0.05)$ and 


\section{REGE 29,2}

\begin{tabular}{lccc}
\hline Constructs & CA & CR & AVE \\
\hline Competitor orientation & 0.953 & 0.969 & 0.913 \\
Customer orientation & 0.931 & 0.951 & 0.829 \\
Entrepreneurial orientation & 0.955 & 0.961 & 0.690 \\
Inter-functional coordination & 0.960 & 0.971 & 0.893 \\
\hline
\end{tabular}

\section{8}

Heterotrait-monotrait (HTMT) ratio

Constructs

\section{1}

2

3

Table 2.

Construct reliability and validity for

1. Competitor orientation

2. Customer orientation

3. Entrepreneurial orientation

4. Inter-functional coordination

0.361

0.369

0.779

0.424

0.535

0.468

\begin{tabular}{lccccc}
\hline Structural path & $(\beta)$ & $T$-stats & $P$-values & Decision rule & $f^{2}$ \\
\hline Competitor orientation $\rightarrow$ Entrepreneurial orientation & 0.067 & 0.953 & 0.341 & Not supported & 0.003 \\
Customer orientation $\rightarrow$ Entrepreneurial orientation & 0.251 & 3.740 & 0.000 & Supported & 0.062 \\
Inter-functional coord. $\rightarrow$ Entrepreneurial orientation & 0.280 & 3.688 & 0.000 & Supported & 0.039 \\
\hline
\end{tabular}

Table 3.

Structural model results for Model 2

\begin{tabular}{lccc}
\hline Construct & $R^{2}$ & $R^{2}$ adjusted & $Q^{2}$ \\
\hline Entrepreneurial orientation & 0.256 & 0.250 & 0.159 \\
\hline
\end{tabular}

inter-functional coordination $(\beta=0.280 ; t=3.688 ; p=0.000<0.05)$ had a significant positive relationship with EO. However, competitor orientation $(\beta=0.067 ; t=0.953 ; p=0.341>0.05)$ did not have a significant nexus with EO. This probably may be because owners of the SMEs think that having knowledge of their customers demand and diffusion of the information to every department is enough to conceptualise ideas necessary for their establishments. It is expected that since $\mathrm{MO}$ showed positive significant relation with the dependent variable, the same should have been the case for its constituents. However, as different countries have differing cultural set-ups, there is a possibility that the components may not behave the same in different settings. Thus, it may be the reason why Ramirez et al. (2014) examined MO's construct in its composite form. The decision that could be reached based on the findings is that not all the elements of $\mathrm{MO}$ have a significant and positive association with EO; hence, $\mathrm{H} 2$ is thus not supported.

\section{Estimation of the model's predictive accuracy}

From Table 3, the coefficient of determination based on the $R^{2}$ result was 0.256 . This means that the three exogenous variables weakly explain $25.6 \%$ of the variation of $\mathrm{EO}$. The results further indicate that the $f^{2}$ of the three exogenous constructs on EO were small. This is because the $f^{2}$ of competitor orientation, customer orientation and inter-functional coordination were $0.003,0.062$ and 0.039 respectively. However, the predictive relevance of the exogenous variables on $\mathrm{EO}$ was medium.

Considering the results of Models 1 and 2, it can be established that owners of SMEs, for improving their EO, should employ $\mathrm{MO}$ in its composite form. This conclusion was reached 
because the $R^{2}, f^{2}$ and $Q^{2}$ values of MO in its composite form on $\mathrm{EO}$ were higher compared to $R^{2}, f^{2}$ and $Q^{2}$ values of components of MO on EO. This agrees with Ramirez et al.'s (2014) result obtained after examining MO's construct in its composite form on EO. This shows the importance of MO in predicting EO. Regardless of the aforementioned conclusion, knowledge of each component's contribution to changes in $\mathrm{EO}$ is required to enable owners of SMEs to know the level of attention to be placed on each component. Without this study, the owners of SMEs will place equal attention on each component.

One of the key contributions of this study is that owners of SMEs and other practitioners will be guided on how to improve their EO through MO. Through this study, they will know that deployment of MO in its composite form rather than components is the best way of improving EO. Owners of SMEs will also know that for improving EO, more attention must be paid to customer orientation and inter-functional coordination. Another contribution of this study is that literature will see an expansion of the study's findings, and this opens replication doors for future researchers in different settings.

\section{Measurement model assessment (model 3)}

The third model examined the influence of $\mathrm{EO}$ on MO. This was examined to determine whether EO can also influence MO. Comparing the results of this model and the findings established in Model 1, it can be ascertained whether interactions exist between the constructs. The extent of the interactions will also be identified, and this will guide SME owners on the order to be followed in the use of these performance differential resources.

\section{Item loading}

The loadings of the indicators of the constructs were examined to determine those to be retained in the model and those to be deleted from it. After the examination, eight out of fifteen and ten out of fourteen indicators of $\mathrm{EO}$ and $\mathrm{MO}$, respectively, were retained in the model. The remaining were deleted from the model because they failed to meet the indicator loadings cut-off point recommended by Hair et al. (2014).

\section{Construct reliability and validity}

The findings of CA, CR and AVE of Model 3 are captured in Table 4. The results indicate that the measurement model met the set criteria as recommended by Hair et al. (2014) and thus has no problem regarding reliability and validity. Based on this, further analysis were undertaken to determine DV and the influence of $\mathrm{EO}$ on MO.

\begin{tabular}{|c|c|c|c|c|c|}
\hline Constructs & $\mathrm{CA}$ & & $\mathrm{CR}$ & & AVE \\
\hline Entrepreneurial orientation & 0.952 & & 0.960 & & 0.750 \\
\hline Market orientation & 0.942 & & 0.950 & & 0.657 \\
\hline Structural path & ( $\beta)$ & $T$-stats & $P$-value & Decision & $f^{2}$ \\
\hline Entrepre. orientation $\rightarrow$ Market orientation & 0.524 & 13.864 & 0.000 & Supported & 0.378 \\
\hline$R$ squared & \multicolumn{3}{|c|}{ Adjusted $R$ squared } & \multicolumn{2}{|c|}{$Q$ squared } \\
\hline 0.274 & \multicolumn{3}{|c|}{0.272} & \multicolumn{2}{|c|}{0.166} \\
\hline
\end{tabular}

Table 4.

Measurement and structural model results for Model 3 
REGE

29,2
Discriminant validity

Sarstedt et al. (2014) recommended that HTMT ratio of $<0.85$ should be the cut-off point in determining DV of the constructs. In the light of this recommendation, it can be concluded based on the DV result of the model captured in Table 4 that the constructs are different from each other. Therefore, the model is devoid of DV problem.

Significance of path coefficients

Significance of the path coefficient of Model 3 was examined, and the findings were shown in Table 4. The results revealed that $\mathrm{EO}$ has a significant positive link with $\mathrm{MO}(\beta=0.524$; $t=13.864 ; p=0.000<0.05$ ). Therefore, it can be posited that EO having significant the positive nexus with MO hypothesis is thus supported. Real et al. (2014) posited that firms that are highly entrepreneurial always monitor their market and respond appropriately in order to become customer service leaders. Thus, $\mathrm{EO}$ can be postulated as a driving force of $\mathrm{MO}$ of a firm. This view was re-echoed by Affendy et al. (2015) and Amin et al. (2016) who claim that an $\mathrm{EO}$ is driving $\mathrm{MO}$ of businesses. Relating this findings to what has been established in Model 1 , it can be averred that the two constructs (EO and $\mathrm{MO}$ ) interact with each other. That is, they influence each other. Supporting this claim, Hussain et al. (2015) opined that the two constructs affect each other, have similar characteristics and facilitate the execution of each other and thus relying solely on one orientation and claiming that it would provide superior performance is inadequate. While MO enables the firm to provide enhanced value to clients, EO enables the firm to seek and exploit opportunities in the marketplace. However, the influence of $\mathrm{EO}$ on $\mathrm{MO}$ is greater compared to the reverse. Therefore, when owners of SMEs are deploying the two constructs in their businesses, EO should precede MO. The finding is another novelty of this study. Through this result, the owners of SMEs will have knowledge of deploying EO before MO during the employment of the two constructs in their firms. The study will also expand the literature with the knowledge of the interactions among the study's constructs.

\section{Estimation of the model's predictive accuracy}

Table 4 captures results of $R^{2}, f^{2}$ and $Q^{2}$ of the relationship between EO and MO. From the results, EO explains approximately $27 \%$ of the variations in MO. Again, EO was found to have a large $f^{2}(0.378)$ on the MO construct with medium predictive relevance. This is because the $Q^{2}$ of the exogenous variable was 0.166 . Though the $R^{2}, f^{2}$ and $Q^{2}$ values of Model 1 were all adequate (Hair et al., 2014), these values were all smaller than that of Model 3. This reiterates the importance of employing EO before $\mathrm{MO}$ when the two constructs are to be deployed by an organisation. It is not surprising that many researchers (Real et al., 2014; Affendy et al., 2015; Amin et al., 2016) supported this claim.

\section{Measurement model assessment (model 4)}

Model 4 marks the final model, and it examines the influence of EO's components on MO. Through the examination of this model, the contribution of each of the components to changes in MO would be ascertained. The analysis of this model will acquaint SME owners and other practitioners of the EO's components, which have the highest influence on the MO. This will direct SME owners on the components in which to place more emphasis.

\section{Item loading}

The criterion posited by Hair et al. (2014) was followed to determine indicators of the constructs to be excluded from the model. Following the criterion, only one item of innovativeness and competitive aggressiveness respectively were excluded from the model. 
Construct reliability and validity

Table 5 depicts the reliable criteria of CA, CR and AVE for the study's constructs. This is because the $\mathrm{CA}, \mathrm{CR}$ and $\mathrm{AVE}$ of the measurement model met the set criteria as recommended by Hair et al. (2014) and thus has no problem regarding reliability and validity. Based on this outcome, further analysis of the model was done.

\section{Discriminant validity}

From Table 5, all the values for each of the constructs were below HTMT 0.85 . This is a clear indication that each construct is truly different from each other since it passes the test of recommendation by Sarstedt et al. (2014).

\section{Significance of path coefficients}

Table 6 further revealed that three dimensions of EO - competitive aggressiveness $(\beta=-0.168 ; t=2.240 ; p=0.026<0.05)$, innovativeness $(\beta=0.163 ; t=2.153$; $p=0.032<0.05)$ and pro-activeness $(\beta=0.358 ; t=3.847 ; p=0.000<0.05)$ - had a significant effect on $\mathrm{MO}$ except that competitive aggressiveness negatively affected $\mathrm{MO}$ construct. The result in the table further revealed that autonomy $(\beta=-0.011 ; t=0.126 ; p=0.900>0.05)$ and risk-taking $(\beta=0.131 ; t=1.508 ; p=0.132>0.05)$ as $\mathrm{EO}$ dimensions had no significant

\begin{tabular}{lcrr}
\hline Construct & CA & CR & AVE \\
\hline Autonomy & 0.942 & 0.963 & 0.897 \\
Competitive aggressiveness & 0.884 & 0.918 & 0.850 \\
Innovativeness & 0.913 & 0.958 & 0.920 \\
Market orientation & 0.942 & 0.950 & 0.657 \\
Pro-activeness & 0.942 & 0.963 & 0.896 \\
Risk-taking & 0.949 & 0.967 & 0.908 \\
\hline
\end{tabular}

Heterotrait-monotrait (HTMT) ratio

Constructs 1

2

3

4

5

Autonomy

Competitive aggressiveness

Innovativeness

Market orientation

Pro-activeness

0.561

0.552

0.323

Risk-taking
0.258

0.065

0.433

0.435
0.754
0.508

0.819

0.698
0.540

0.462
Ghanaian

SMEs'

perspective on

$\mathrm{MO}$ and $\mathrm{EO}$

natakn

\begin{tabular}{lccclc}
\hline Structural path & $(\beta)$ & $T$-stats & $P$ values & Decision rule & $f^{2}$ \\
\hline Autonomy $\rightarrow$ Market orientation & -0.011 & 0.126 & 0.900 & Not supported & 0.000 \\
Competitive aggressiveness $\rightarrow$ Market orientation & -0.168 & 2.240 & 0.026 & Not supported & 0.028 \\
Innovativeness $\rightarrow$ Market orientation & 0.163 & 2.153 & 0.032 & Supported & 0.016 \\
Pro-activeness $\rightarrow$ Market orientation & 0.358 & 3.847 & 0.000 & Supported & 0.050 \\
Risk-taking $\rightarrow$ Market orientation & 0.131 & 1.508 & 0.132 & Not supported & 0.008 \\
\hline
\end{tabular}

\begin{tabular}{lccc}
\hline Construct & $R^{2}$ & $R^{2}$ adjusted & $Q^{2}$ \\
\hline Market orientation & 0.304 & 0.294 & 0.182
\end{tabular}

Table 6. Structural model results for Model 4 
REGE

29,2 effect on MO. The decision rule is that $\mathrm{H} 4$ is therefore rejected. The assertion by Real et al. (2014) that firms that are highly entrepreneurial always monitor their market and respond appropriately, in order to become customer service leaders, would make one believe that all EO's elements have positive and significant nexus with MO. Yet, the opposite was ascertained in this study. The key contribution of this finding is that SME owners and researchers will be informed that not all the EO dimensions have positive and significant link with MO. Thus, the practitioners in the sector of SMEs would be guided on how to apportion their time in the adoption of these dimensions in improving MO.

\section{Estimation of the model's predictive accuracy}

In Table 6, the coefficient of determination based on the $R^{2}$ result was 0.304 . This means that the five exogenous variables comprising autonomy, competitive aggressiveness, innovativeness, pro-activeness and risk-taking explain $30.4 \%$ of the variation of the MO. Moreover, Table 6 shows the effect sizes of the various exogenous variables. Autonomy $\left(f^{2}=0.000\right)$ as a dimension of the EO, per the criteria has no effect on MO. The remaining constructs, that is, competitive aggressiveness $\left(f^{2}=0.028\right)$, innovativeness $\left(f^{2}=0.016\right)$, pro-activeness $\left(f^{2}=0.050\right)$ and risk-taking $\left(f^{2}=0.008\right)$ had small effect sizes on the latent variable (MO). Finally, the table indicates that all the exogenous variables were able to moderately predict the model. This is because the $Q^{2}$ of the exogenous variables was 0.182 , thus indicating moderate predictive relevance. Comparing Models 3 and 4 results, it can be asserted that composite influence of $\mathrm{EO}$ on $\mathrm{MO}$ is not the best approach to be adopted. This is because its determination of the changes in the MO is lesser, compared to the combined effect of the components. Thus, EO should be considered as a multidimensional construct. Without this study, the literature would have been limited with the findings of Real et al. (2014) and Amin et al. (2016), in which EO in its composite form was examined on MO.

\section{Conclusion}

The purpose of the study is to examine the interrelationships between MO and EO. The findings of the study established that MO has a significant positive nexus with EO. In the light of the findings, the hypothesis that MO has a significant and positive relationship with EO is thus supported. Therefore, it is recommended that owners of SMEs and other practitioners who intend to improve their $\mathrm{EO}$ should use $\mathrm{MO}$ to meet such purposes. Besides, in examining the relation of MO's components with EO, the findings revealed that customer orientation and inter-functional coordination had a significant positive relationship with EO. However, competitor orientation did not have a significant nexus with EO. This probably may be because owners of the SMEs think that having knowledge of their customers' demand and diffusion of the information to every department is enough to conceptualise ideas necessary for their establishments. The decision that could be reached based on the findings is that not all the elements of $\mathrm{MO}$ have a significant and positive association with EO. Hence, $\mathrm{H} 2$ is thus not supported.

Considering the results of Models 1 and 2, it can be established that owners of SMEs, for improving their EO, should deploy MO in its composite form. This conclusion was reached because the $R^{2}, f^{2}$ and $Q^{2}$ values of MO in its composite form on $\mathrm{EO}$ were higher compared to $R^{2}, f^{2}$ and $Q^{2}$ values of components of MO on EO. This shows the importance of MO in predicting EO. Regardless of the aforementioned conclusion, knowledge of each component's contribution to changes in EO is required to enable owners of SMEs to know the level of attention to be placed on each component. Without this study, the owners of SMEs would have placed equal attention on each component. 
One of the key contributions of this study is that owners of SMEs and other practitioners would be guided on how to improve their EO through MO. Through this study, they would know that deployment of $\mathrm{MO}$ in its composite form rather than components is the best way of improving EO. Owners of SMEs would also know that for improving EO, more attention must be paid to customer orientation and inter-functional coordination. Another contribution of this study is that literature will see expansion of the study's findings, and this opens replication doors for future researchers in different settings.

Furthermore, the nexus of $\mathrm{EO}$ and $\mathrm{MO}$ was examined, and the results revealed that $\mathrm{EO}$ has a significant positive link with MO. Therefore, it can be posited that EO having a significant positive nexus with MO hypothesis is supported. Relating this finding to what has been established in Model 1, it can be averred that the two constructs (entrepreneurial and MOs) interrelate with each other. That is, they influence each other. However, the influence of $\mathrm{EO}$ on $\mathrm{MO}$ is greater compared to the reverse. Therefore, when owners of SMEs are embracing the two constructs in their businesses, EO should precede MO. The finding is another novelty of this study. Through this result, the owners of SMEs will have knowledge of embracing EO before MO during the employment of the two constructs in their firms. The study will also expand the literature with the knowledge of the interactions of the study's constructs.

Finally, the nexus of components of EO and MO were examined. The results revealed that three dimensions of $\mathrm{EO}$ - competitive aggressiveness, innovativeness and pro-activeness - had a significant effect on $\mathrm{MO}$ except that competitive aggressiveness negatively affected the MO construct. The result further revealed that autonomy and risk-taking as EO dimensions had no significant link with MO. The decision rule is that $\mathrm{H} 4$ is therefore rejected. The key contribution of this finding is that SME owners and researchers would be informed that not all of the EO dimensions have a positive and significant link with MO. Thus, the practitioners in the sector of SMEs would be guided on how to apportion their time in the adoption of these dimensions for improving MO. The $R^{2}$ result shows that the five exogenous variables of entrepreneurial construct explain $30.4 \%$ of the variation of the MO. Moreover, $f^{2}$ and $Q^{2}$ results showed that the components had small effect sizes and medium predictive relevance, respectively, with the exception of autonomy, which has no effect on MO. Comparing Models 3 and 4 results, it can be asserted that composite influence of $\mathrm{EO}$ on $\mathrm{MO}$ is not the best approach to be adopted. This is because its determination of the changes in the $\mathrm{MO}$ is lesser, compared to combined effect of its components. Thus, EO should be considered a multidimensional construct.

\section{Recommendations}

The study recommends the concurrent deployment of $\mathrm{MO}$ and $\mathrm{EO}$ by businesses since both interrelate. Also, when owners of SMEs are embracing the two constructs in their businesses, EO should precede $\mathrm{MO}$ due to its contribution in influencing a firm's MO. In addition, owners of SMEs should not place equal attention on each construct and their components during their concurrent employment in the establishments. This is due to the fact that not all the components of $\mathrm{MO}$ have positive and significant influence on $\mathrm{EO}$, and the reverse is true. Finally, it is also recommended to owners of SMEs that when they intend to improve their EO, they should employ MO in its composite form rather than components.

\section{Limitations and suggestions for further studies}

In the light of the conclusions reached by this study, the following limitations and suggestions for future studies were eminent. This study is a cross-sectional one; hence, it would not be able to establish changes in the study's units over a period. In this regard, future researchers should explore the longitudinal approach, which would overcome the challenges 
REGE 29,2 of cross sectional approach. Furthermore, the current study could not capture the SMEs in the entire country. In this regard, scholars should consider replicating the current study by capturing SMEs in the entire country and have their results compared to that of the current study. Finally, since the current study could not cover all the sectors of the Ghanaian economy, its replication should be done in other sectors of the economy in the future.

\section{References}

Acquah, I. S. K., Essel, D., Baah, C., Agyabeng-Mensah, Y., \& Afum, E. (2021a). Investigating the efficacy of isomorphic pressures on the adoption of green manufacturing practices and its influence on organizational legitimacy and financial performance. Journal of Manufacturing Technology Management, 32(7), 1399-1420.

Acquah, I. S. K., Naude, M. J., \& Sendra-García, J. (2021b). Supply chain collaboration in the petroleum sector of an emerging economy: Comparing results from symmetrical and asymmetrical approaches. Technological Forecasting and Social Change, 166, 120568.

Affendy, A. H., Asmat-Nizam, A. T., \& Farid, M. S. (2015). Entrepreneurial orientation effects on market orientation and SMEs business performance - A SEM approach. Review of Integrative Business and Economics Research, 4(3), 259-271.

Agbegblewu, S., \& Boohene, R. (2016). The interactions between entrepreneurial orientation, firm resources and the performance of tourist accommodations in the central region of Ghana. International Journal of Strategic Organisation and Behavioural Science, 5(1-2), 3-16.

AGI. (2018). Association of Ghana industries data on SMEs. Accra: AGI.

Al Mamun, A., \& Fazal, S. A. (2018). Effect of entrepreneurial orientation on competency and microenterprise performance. Asia Pacific Journal of Innovation and Entrepreneurship, 12(3), 379-398.

Amin, M., Thurasamy, R., Aldakhil, A. M., \& Kaswuri, A. H. B. (2016). The effect of market orientation as a mediating variable in the relationship between entrepreneurial orientation and SMEs performance. Nankai Business Review International, 7(1), 39-59.

Asomaning, R., \& Abdulai, A. (2015). An empirical evidence of the market orientation-market performance relationship in Ghanaian small businesses. Educational Research International, 4(2), 69-86.

Awang, A., Amran, S., Nor, M. N. M., Ibrahim, I. I., \& Razali, M. F. M. (2016). Individual entrepreneurial orientation impact on entrepreneurial intention: Intervening effect of $\mathrm{PBC}$ and subjective norm. Journal of Entrepreneurship, Business and Economics, 4(2), 94-129.

Bature, S. W., \& Hin, C. W. (2017). EO, learning orientation, technology orientation, access to debt finance and firm performance: A proposed research framework. International Business Management Journal, 11(2), 444-453.

Boso, N., Oghazi, P., Cadogan, J. W., \& Story, V. M. (2016). Entrepreneurial and market- oriented activities, financial capital, environment turbulence, and export performance in an emerging economy. Journal of Small Business Strategy, 26(1), 1-24.

Cano, C. R., Carrillat, F. A., \& Jaramillo, F. (2004). A meta-analysis of the relationship between market orientation and business performance: Evidence from five continents. International Journal of Research in Marketing, 21(2), 179-200.

Cohen, M. A. (1988). Some new evidence on the seriousness of crime. Criminology, 26(2), 343-353.

Couto, G., Sousa, Á., \& Pimentel, P. (2017). Exploring the characteristics of potential entrepreneurs: An empirical study. Journal of Entrepreneurship, Business and Economics, 5(2), 1-18.

Cooper, D. R., \& Schindler, P. S. (2001). Business research methods (7th ed.). Boston: McGraw-Hill Higher Educational Learning.

Covin, J. G., \& Slevin, D. P. (1989). Strategic management of small firms in hostile and benign environments. Strategic Management Journal, 10(1), 75-87. 
de Lara, F. F., \& Guimarães, M. R. N. (2018). The influence of the specifics of small businesses on innovation: A multiple case study of the Brazilian metal-mechanical industry. Revista de Gestão, 25(3), 242-257.

dos Santos, I. L., \& Marinho, S. V. (2018). Relationship between entrepreneurial orientation, marketing capability and business performance in retail supermarkets in Santa Catarina (Brazil). Innovation and Management Review, 15(2), 118-136.

Garcia, V. M. B., Martens, C. D. P., Carvalho, R. B., \& Martens, M. L. (2021). Contributions of entrepreneurial orientation in the use of agile methods in project management. Innovation and Management Review, 18(1), 17-33.

Gholami, S., \& Birjandi, M. (2016). The effect of market orientation and entrepreneurial orientation on the performance of SMEs. Journal of Current Research in Science, 3(1), 361-369.

Gruber-Muecke, T., \& Hofer, K. M. (2015). Market orientation, entrepreneurial orientation and performance in emerging markets. International Journal of Emerging Markets, 10(3), 560-571.

Hair, J. F., Hult, G. T. M., Ringle, C. M., \& Sarstedt, M. (2014). A primer on partial least squares structural equation modelling. Thousand Oaks, CA: Sage Publications.

Henseler, J., Ringle, C. M., \& Sinkovics, R. R. (2009). The use of partial least squares path modeling in international marketing. New Challenges to International Marketing, Emerald Group Publishing, 20(1), 277-319.

Hussain, J., Ismail, K., \& Shah, F. A. (2015). The effect of market and entrepreneurial orientations on organisational performance: Study of Malaysian SMEs. City University Research Journal, 5(2), 203-218.

Issau, K. (2019). Role of market orientation on innovation orientation of manufacturing small and medium-sized enterprises (SMEs) in the Accra Metropolis, Ghana. Journal of Entrepreneurship and Business, 7(1), 40-51.

Issau, K., Acquah, I. S. K., Gnankob, R. I., \& Hamidu, Z. (2021). Innovation orientation and performance of small and medium-sized enterprises (SMES) in Ghana: Evidence from manufacturing sector. Innovation and Management Review, Advance online publication. doi: 10.1108/INMR-07-2020-0092.

Issau, K., \& Soni, S. (2019). Business orientation and performance of small and medium-sized enterprises: Evidence from Ghana. African Journal of Business and Economic Research, 14(4), 53-79.

Kayanula, D., \& Quartey, P. (2000). The policy environment for promoting small and medium-sized enterprises in Ghana and Malawi, Finance and Development Research Programme. Working Paper Series, Paper No 15, IDPM, University of Manchester.

Kemelgor, B. H. (2002). A comparative analysis of corporate entrepreneurial orientation between selected firms in the Netherlands and the USA. Entrepreneurship and Regional Development, 14(1), 67-87.

Kim, S. (2018). Domains and trends of entrepreneurship research. Management Review: An International Journal, 13(1), 65-90.

Kohli, A. K., \& Jaworski, B. J. (1990). Market orientation: The construct, research propositions, and managerial implications. The Journal of Marketing, 54(2), 1-18.

Lingelbach, D. C., De La Vina, L., \& Asel, P. (2005). What's distinctive about growth-oriented entrepreneurship in developing countries? SSRN Electronic Journal, 1(1), 1-10.

Long, H. C. (2013). The relationship among learning orientation, market orientation, entrepreneurial orientation, and firm performance of Vietnam marketing communication firms. Philippine Management Review, 20(1), 37-46.

Lonial, S. C., \& Carter, R. E. (2015). The impact of organisational orientations on medium and small firm performance: A resource-based perspective. Journal of Small Business Management, 53(1), 94-113.

Lumpkin, G. T., \& Dess, G. G. (1996). Clarifying the EO construct and linking it to performance. Academy of Management Review, 21(1), 135-172. 
REGE

29,2
Machado, H. P. V., Gaiotto, S. A. V., \& Machado, M. C. R. (2021). Growth and social entrepreneurs: The challenge of conciliating economic and social values. Revista de Gestão, 28(1), 2-22.

Miller, D. (2011). Miller (1983) revisited: A reflection on EO research and some suggestions for the future. Entrepreneurship Theory and Practice, 35(5), 873-894.

Moghadam, S. J., \& Salamzadeh, A. (2018). Do senior bankers care about entrepreneurial behaviour?: Case of senior managers of Iranian vanguard banks. World Review of Entrepreneurship, Management and Sustainable Development, 14(1-2), 271-287.

Narver, J. C., \& Slater, S. F. (1990). The effect of a market orientation on business Profitability. The Journal of Marketing, 54(4), 20-35.

Nasir, W. M. N. B. W. M., Al Mamun, A., \& Breen, J. (2017). Strategic orientation and performance of SMEs in Malaysia. SAGE Open, 7(2), 1-13.

NBSSI. (2018). National board for small scale industries data on SMEs. Accra: NBSSI.

Neuman, W. L. (2014). Social reseach methods: Qualitative and quantitative approaches (7th ed.). Harlow: Pearson Education.

Noble, C. H., Sinha, R. K., \& Kumar, A. (2002). Market orientation and alternative strategic orientations: A longitudinal assessment of performance implications. Journal of Marketing, 66(4), 25-39.

Ocloo, C. E., Akaba, S., \& Worwui-Brown, D. K. (2014). Globalization and competitiveness: Challenges of small and medium enterprises (SMEs) in Accra, Ghana. International Journal of Business and Social Science, 5(4), 287-296.

Opoku, M. (2017). The effect of strategic planning on SMEs performance: A case study of selected SMEs in Kumasi. Doctoral dissertation, Kwame Nkrumah University of Science and Technology.

Pelham, A. M. (2000). Market orientation and other potential influences on performance in small and medium-sized manufacturing firms. Journal of Small Business Management, 38(1), 48-67.

Peteraf, M. A., \& Barney, J. B. (2003). Unravelling the resource-based tangle. Managerial and Decision Economics, 24(4), 309-323.

Prifti, R., \& Alimehmeti, G. (2017). Market orientation, innovation, and firm performance - An analysis of Albanian firms. Journal of Innovation and Entrepreneurship, 6(1), 1-19.

Rahman, N. A., Yaacob, Z., \& Radzi, R. M. (2016). The challenges among Malaysian SME: A theoretical perspective. World, 6(3), 124-132.

Ramirez, R. G., Guzman, G. M., \& Serna, M. D. C. M. (2014). The relationship between market orientation, entrepreneurial orientation, and innovation: Evidence from Mexican SMEs. Journal of Business and Economics, 5(16), 1930-1940.

Rauch, A., Wiklund, J., Lumpkin, G. T., \& Frese, M. (2009). Entrepreneurial orientation and business performance: An assessment of past research and suggestions for the future. Entrepreneurship Theory and Practice, 33(3), 761-787.

Real, J. C., Roldán, J. L., \& Leal, A. (2014). From EO and learning orientation to business performance: Analysing the mediating role of organisational learning and the moderating effects of organisational size. British Journal of Management, 25(2), 186-208.

Salamzadeh, A., Farjadian, A., Amirabadi, A., \& Modarresi, M. (2014). Entrepreneurial characteristics: Insights from undergraduate students in Iran. International Journal of 1 'Entrepreneurship and Small Business, 21(2), 165-182.

Sarstedt, M., Ringle, C. M., Smith, D., Reams, R., \& Hair, J. F., Jr (2014). Partial least squares structural equation modeling (PLS-SEM): A useful tool for family business researchers. Journal of Family Business Strategy, 5(1), 105-115.

Saunders, M., Lewis, P., \& Thornhill, A. (2016). Research methods for business students. Harlow: Pearson Education. 
Sekaran, U., \& Bougie, R. (2016). Research methods for business: A skill building approach (7th ed.). New Jessey: John Wiley and Sons.

Shehu, A. M. (2014). The relationship between market orientation and firm performance: A look at Nigerian SMEs. Developing Country Studies, 4(12), 87-93.

Tajpour, M., \& Hosseini, E. (2021). Entrepreneurial intention and the performance of digital startups: The mediating role of social media. Journal of Content, Community and Communication, 13, $2-15$.

Tajpour, M., Hosseini, E., \& Alizadeh, R. (2021). Entrepreneurship opportunities: The effect of social entrepreneurship on the presence of Afghan immigrant youth in Iranian universities. Migration Social Entrepreneurship and Social Inclusion, 1, 261-284.

\section{Corresponding author}

Kassimu Issau can be contacted at: kissau@ucc.edu.gh

Associate Editor: Aidin Salamzadeh

For instructions on how to order reprints of this article, please visit our website: 